\title{
PERBANDINGAN DUA PRODUK DIGITAL CONTROL SYSTEM
}

\author{
Dicky Suryapranatha ${ }^{1}$, \\ ${ }^{1}$ Jurusan Teknik Industri,Fakultas Teknik dan Ilmu Komputer,Universitas Buana Perjuangan \\ KarawangJl. HS. Ronggowaluyo Telukjambe Timur Karawang \\ Email: Dicky.Suryapranatha@ubpkarawang.ac.id
}

\begin{abstract}
Digital Control System (DCS) is a very important tool for manufacturing companies that implement automation systems in their production processes, so companies must be careful when deciding to purchase DCS tools offered by vendors. This study aims to compare two Digital Control System (DCS) devices from international suppliers using temperature comparison variables, data processing speed and data transfer speed. After the data collected is tested for validity and reliability, then a T test is carried out to compare these variables and a direct comparison of the material specifications of the two tools is carried out. The results of the Benchmarking study are that there is a difference in the temperature and data processing speed variables between the two DCS devices, while for the data transfer rate variable there is no difference. This difference occurs because the data computing process is more and more data computing is needed, the temperature will increase and for data processing speed there is no difference because it uses the same technology. To improve the capabilities of the DCS tool, it is necessary to redesign for the controller, design panels and use the latest data transfer technology and data security systems in data transfer.
\end{abstract}

Keywords: Benchmarking; Digital Control System; Temperature; Speed of process

\begin{abstract}
ABSTRAK
Digital Control System (DCS) merupakan alat yang sangat penting untuk perusahaan manufaktur yang menerapkan sistem otomasi dalam proses produksinya, sehingga perusahaan harus berhati hati saat memutuskan untuk pembelian alat DCS yang ditawarkan oleh vendor. Penulisan ini bertujuan untuk Benchmarking dua alat Digital Control System (DCS) yang diproduksi oleh dua perusahaan internasional dengan menggunakan variable pembanding temperatur, Kecepatan prosesdata dan kecepatan transfer dat. Setelah data yang dikumpulkan di uji Validitas dan Realibilitas, selanjutnya dilakukan Uji T untuk membandikan variabel variabel tersebut serta dilakukan perbandigan langsung spesifiksi material dari kedua alat tersebut. Hasil studi Benchmarking menunjukan bahwa ada perbedaan pada variabel temperatur dan kecepatan proses data antara kedua alat DCS, sedangkan untuk variabel kecepatan transfer data tidak ada perbedaan antara kedua alat tersebut. Perbedaan tersebut terjadi akikat proses komputasi data semakin banyak diperlukan komputasi data maka temperatur akan meningkat dan untuk kecapatan proses data tidak ada perbedaan karena menggunakan teknologi yang sama. Untuk meningkatkan kemampuan dari alat DCS maka diperlukan Redesign untuk kontroler,design panel dan pengunnan teknologi transfer data terbaru serta sistem keamanan data dalam transfer data.
\end{abstract}

Kata kunci: Benchmarking; Digital Control System; Temperatur; Kecepatan proses;

\section{PENDAHULUAN}

Dalam usaha untuk meningkatkan efisiensi dan efektifitas proses industri, banyak perusahaan mempertimbangkan untuk menggunakan sistem otomasi dalam proses produksi yang 
bertujuan untuk mengurangi kesalahan dalam melakukan proses produksi dengan sistem yang terintegrasi. Karena kebutuhan proses otomatisasi maka industri manufaktur yang memproduksi peralatan kontrol otomasi saat ini berkembang dengan pesat dan banyak sekali produk yang dikeluarkan oleh perusahaan internasional untuk memenuhi kebutuhan penggunaan sistem otomasi pada perusahaan perusahaan di Indonesia, karena semakin banyak vendor sistem otomasi ini maka perusahaan mulai kesulitan untuk menentukan dan mendapatakan produk dan vendor sistem otomasi yang dapat digunakan di perusahaan mereka.

Dalam usaha mendapatkan vendor otomasi ini diperlukan proses pembandingan (Benchmark) yang cermat agar didapatkan produk yang sesuai dengan kebutuhan dari industri yang akan dikembangkan dan berdasar budget yang dimiliki perusahaan tersebut.

Pada saat ini sudah banyak perusahaan yang bergerak di bidang peralatan kontrol otomasi diantaranya Honeywell, Yokogawa, Rosemont dan ABB, perusahaan tersebut sudah mulai masuk ke Indonesia sejak tahun 1980 dimana saat itu Indonesia mulai mengembangkan pertambangan industri minyak dan gas serta industri hilir lainnya seperti industri pupuk dan petrochemical yang berkembang pesat. Saat itu hanya perusahaan yang bermodal besar saja yang bisa menggunakan teknologi otomasi tetapi seiring berjalan nya waktu maka teknologi ini bisa dimanfaatkan oleh semua jenis industri manufaktur. Pembuantan Benchmarking produk otomasi ini diperlukan dalam rangka mendapatkan produk otomatisasi yang dapat digunakan untuk aplikasi di pembangkit tenaga listrik untuk memenuhi permintaan listrik serta mendukung pertumbuhan ekonomi PLN mendapat tugas melalui Peraturan Presiden No 71/2006 yang dirubah dengan Perpres No 59/2009 untuk membangun sejumlah pembangkit listrik berbahan bakar Batu Bara 10 di pulau jawa dan 26 di luar pulau jawa beserta transmisinya.

Berkembangnya teknologi sistem otomasi di industri menyebabkan banyak industri manufaktur otomasi berusaha memberikan perlayanan yang lebih baik agar bisa memuaskan konsumen, mulai dari peningkatan kemampuan alat sampai pelayanan purna jual seterlah produk dipasang dan ini meningakatkan persaingan antara produsen produk sistem otomasi. Salah satu produsen sistem otomasi yaitu Honeywell mengalami persaingan yang sangat ketat terlihat dari survey tahun 2012 banyak produk Honeywell berada di bawah Emerson selaku kompetitornya “ Review Michael.G (2013) Leadership in automation;First Team Honorees Automation Words Retrive from HTTP://www.Automationworld.com Untuk mendapatkan sistem otomasi yang baik diperlukan suata acuan yang bisa dipakai untuk menentukan produk dari vendor mana yang akan cocok digunakan pada industri pembangkit listrik yang disebutkan diatas serta industri menengah lain yang sedang berkembang pesat saat ini di Indonesia. Untuk permasalahan yang sering terjadi pada pemilihan produk tersebut adalah

Menentukan jenis atau tipe sistem otomasi yang cocok pada aplikasi di industri beserta fungsi dan keunggulan komponen dari sistem otomasi setiap vendor.

Tidak ada daftar khusus untuk yang dapat dijadikan acuan untuk menentukan tipe kontrol otomasi yangdiperlukan oleh industri tersebut.

Dari hal diatas maka penelitan ini bertujuan untuk mendapatkan suatu standar sistem kontrol otomasi yang sesuai dengan kebutuhan sehingga produk yang dipasang bisa bekerja dengan kemampuan maksimal serta pada keadaan proses industri dari hal itu penulis menitikberatkan penelitian dengan tujuan

Melakukan perbandingan (Bechmarking) untuk mendapatakan kelebihan dan kekurangan dua produk Digital Control System (DCS) yang banyak di gunakan di Industri.

Mementukan indikator atau variabel apa saja dalam sistem DCS yang berbeda lalu melakukan Analisa perbedaan variabel yang dikumpulkan.

Mendapatkan produk DCS yang terbaik yang cocok untuk industri menengah serta membantu vendor vendor tersebut untuk mengembangkan produk sehingga bisa menjadi pimpinan dalam penjualan dan pemakaian produk DCS di perusahaan

Dikarenakan penelitian produk otomasi ini sangat banyak penulis hanya melakukan perbandigan untuk produk Digital Control System (DCS) serta banyak nya komponen dari sistem ini penulis juga melakuan asumsi dan pembatasan masalah sebagai berikut untuk menjaga penulisan lebih terarah.

Penelitian ini hanya mengambil data sistem otomasi pada sistem DCS yang berkerja secara normal dan mengambil variabel yang ditentukan sebelumnya untuk menentukan kelayakan suatu produk. 
Penelitian hanya dilakukan untuk mendapatkan spesifikasi terbaik konsumen DCS yang bisa diaplikasikan pada industri pembangkit tenaga listrik dan industri menengah sehingga didapat produk yang lebih baik dan bisa diterima konsumen.

Proses Benchmarking ini hanya dilakukan pada dua produk DCS dimana pada penulisan ini ditulis produk DCS A dan DCS B.

\section{METODE PENELITIAN}

Dalam melakukan penelitian ini penulis membuat alur penelitian membandingkan dua produk DCS ini sebagai berikut:

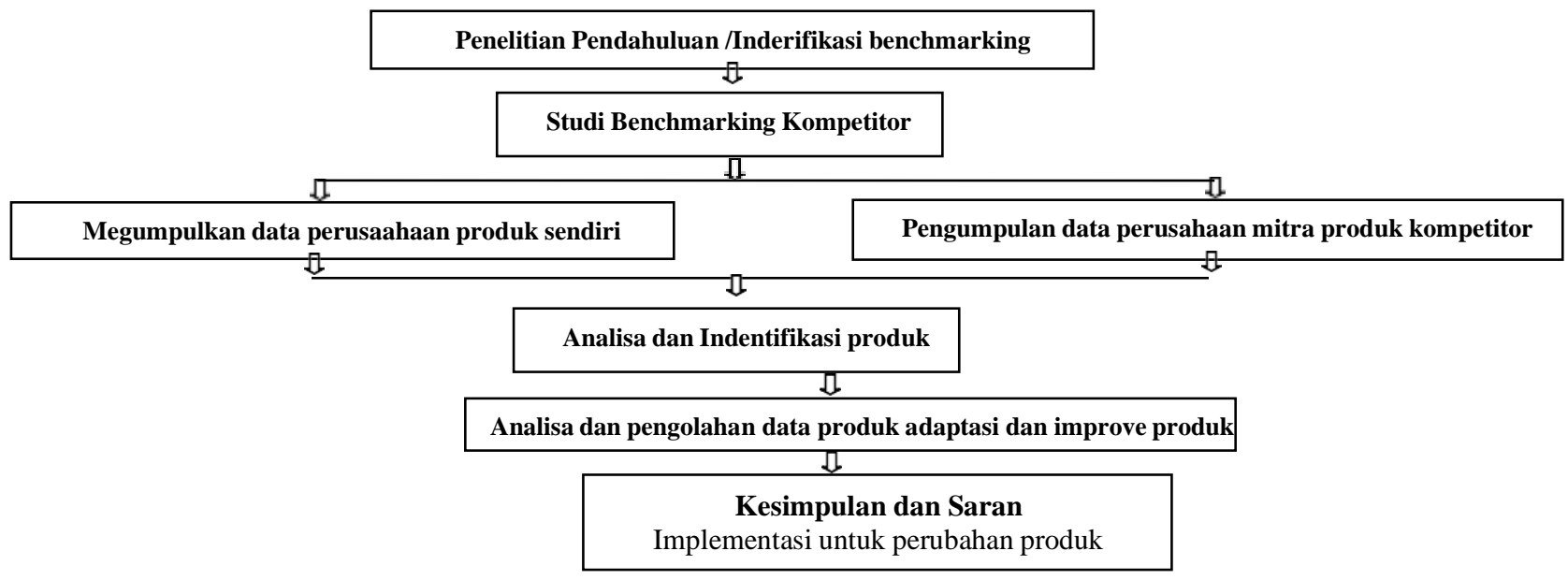

Gambar 1. Flow Chart Perbandingan Dua Alat Digital Control System

Penelitian dilakukan pada produk Distributed Control System (DCS) dimana untuk proses benchmarking secarafungsional untuk mendapatkan suatu strategi guna mempebaiki kualitas produk yang diawali dari studi literatur sampai menetapkan kesimpulan untuk penelitian selanjutnya, untuk melakukan penelitian penulis mengumpulkan data dengan melakukan test alat secara langsung menggunakan simulator alat sehingga didapat spesifikasi teknis untuk dilakukan benchmarking dan selain menggunakan test menggunakan simulator penulis juga mengumpulkan data sekunder untuk melakukan benchmarking produk tersebut.

Data sekunder tersebut diperoleh dengan cara menyimpan alat pengukur kecepatan dan tempertatur pada alat yang dijalanan terus menerus selama penelitian produk.Untuk mengumpulkan data kecepatan alat dan data temperatur menggunakann alat Online Diagnostic Unit dan Software Perfomance Test dikeluarkan oleh prosoft. Selain melakukan pengukuran data dilakukan juga pengumpulan data untuk mempermudah benchmarking sebagai berikut:

Data umum klasifikasi produk, informasi perusahaan yang memproduksi DCS dan sejarah perkembagan produk DCS.

Data Spesifikasi produk DCS informasi system konfigurasi produk, arsitektur produk, komponen pendukung, komponen tambahan dan aplikasi tambahan dari produk.

Dari penelitian sebelumnya dengan adanya peningakatan kecepatan proses data maka mempengaruhi peningkatan temperatur dari suatu alat hal ini dikarenakan meningkatnya daya arus saat memproses data, berikut data yg dikumpulkan jadi variabel pembanding. Temperatur controller dimana data temperature ini didapat dengan memasang alat bantu di controller untuk memonitorig temperature secara online, Data yang diambil lebih dari 400 sampling data diambil secara online setiap 5 menit selama 2 hari maka didapat lebih 400 poin data.

Kecepatan proses data adalah data yang didapat dengan menggunakan software bantuan dalam system controller, alat ini bias mengetahui berapa rata rata kecepatan processor dari controller saat melakukan kalkulasi data, pegumpulan data didapat lebih 100 sampel untuk penelitian ini penulis hanya mengambil poin data yang maksimal saat pengukuran tersebut.

Kecepatan transfer data (Network Speed) untuk mengetahui proses kalkulasi data yang didapat 
menggunakan suatu software bantuan dimana hanya mengambil poin poin yang maksimal dan searah waktunya dengan waktu kecepatan proses yang jumlah data sebanyak 30 sampel

Setelah data dikumpulkan penulis melakukan Analisa data dengan melakukan bebarapa hal sebagai berikut untuk bias dijadikan perbandingan produk DCS:

Melakukan uji validitas dan realibilias data yang didapat untuk memastikan data yang didapat bisa digunakan.

Untuk data temperatur, kecepatan transfer data dan kecepatan proses data dilakukan pengolahan datan dengan menggunakan uji-t berpasangan di bandingkan antar kedua produk. Bila ada perbedaan maka ketiga variabel bisa dijadikan acuan untuk meningkatkan performa.

Hasil dari pengumpulan data dilakukan pengujian menggunakan test-t dengan 2 arah dimana hipotesis dua arah digunakan untuk melihat apakah nilai rata rata sampel tunggal sama dengan acaua atau tidak sama dengan

$H_{0}: x_{1}=x_{2}$ (Rata-rata sampel $=$ nilai acuan

$H_{0}: x_{1 \neq x_{2}}$ (Răta-rata sampel $\neq$ nilai acuan)

Pengujian hipotesis kriteria penolakan atau Penerimaan $\mathrm{H}_{0}$ adalaha berdasarkan nilai P-Value atau nilaiT-Tabel ktriteria tersebut adalah sebagai berikut

Jika Nilai $P$-Value $(S i g)<\alpha$ (Biasanya 5\%), maka $H_{0}$ ditolak Jika Nilai

$P$-Value (Sig) $>\alpha($ Biasanya $5 \%)$, maka $H_{0}$ diterima

Dan Jika Nilai $t$-hitung $>t$-tabel, maka $H O$ ditolak Jika

Nilai $t$-hitung $<t$-tabel, maka $H_{0}$ diterima

Berikut adalah langkah

melakukan Uji-T Unequal $\mathrm{T}$

$$
\begin{gathered}
t=\frac{\bar{x}_{1}-\bar{x}_{2}}{\sqrt{\left(\frac{\left(n_{1}-1\right) s_{1}^{2}+\left(n_{2}-1\right) s_{2}^{2}}{\left(n_{1}-1\right)+\left(n_{2}-1\right)}\right)\left(\frac{1}{n_{1}}+\frac{1}{n_{2}}\right)}} \\
d f=n_{1}+n_{2}-2
\end{gathered}
$$

Test

Dimana :

$\mathrm{t}=\mathrm{t}$ Hitung harga yang dihitung menunjukan standar

deviasi distribusi $\mathrm{tx}_{1}=$ Rata-rata nilai yang diperoleh dari

hasil pengumpulan data 1

$\mathrm{S}_{2}=$ Rata-rata nilai yang diperole $\mathrm{h}_{2}$ darihanasil pengumpulan data 2

$\mathrm{N}_{1}=$ Jumlah sampel penelitian $1 \mathrm{~N}_{2}=$ Jumlah sampel penelitian 2

$d f=$ Degree of Fredom derajat kebebaan

\section{HASIL DAN PEMBAHASAN}

Latar belakang Produk Perbandingan Dua alat Digital Control System (DCS) ini diperlukan sebagai alat membandingkan kedua produk tersebut dimana ada dua jenis produk yang penulis bandingkang yaitu DCS OVT8 dan DCS EXP8 berikut latar belakang dari kedua produk tersebut OVT8 dikembangkan perusahaan ER yang menawarkan OVT8 sebagai alat kontrol pembangkit listrik dan kontrol air limbah dan sudah dipasang di 3.000 sistem di seluruh dunia.OVT 8 dipekernalkan mulai tahun 1997 dan terus berevolusi untuk menggabungkan teknologi baru dan kemampuan yang dirancang sesuai kebutuhan operasional unik suatu pembangkit listrik, saat ini upgrade OVT 8 mempunyai fasilitas Virtual Engineeringyang menggabungkan simulasi teknologi virtual untuk 20 simulasi controller dan OVT8 sehingga mampu untuk membuat,menguji,memverifikasi dan unduh proses grafis, kontrol logika dan data base tanpa mempengaruhi operasi pabrik. OVT8 memilik sistem keamanan komunikasi data terbaru yang mampu mendeteksi,menganalisa masalah dalam sistem operasi, konfigurasi dan perangkat lunak lainnya, OVT8 juga mempunyai kemampuan alarm analisis secara statistik dengan memanfaatkan informasi sebelumnya yang dikumpulkan. Berikut tampilan produk dan sistem konfigurasi: 


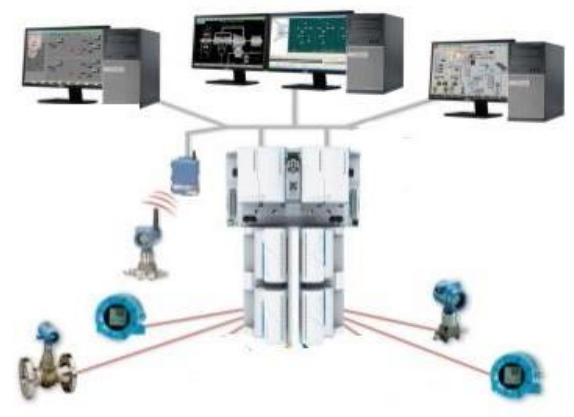

\section{Gambar 2. System arsitektur OVT8}

EXP8 dikembangkan oleh perusahaan HL yang digunakan secara luas sebagai alat engineering control sebagai suatu terobosan paket pengedalian terdistribusi (DCS) dan Supervisory Control and Data Acquisition (SCADA) topologi menjadi satu sistem,Platform EXP8 berhasil diluncurkan pada tahun 2003 yang dikenal sebagai alat yabg efektif di dunia industri karena cocok untuk area yang lebih kecil, menawarkan proses kontrol yang kuat dan fitur kontrol batch. Pengembang EXP8 mengklaim bahwa EXP8 mampu membantu industri menghemat ribuan dolar setiap tahun karena sistem EXP8 mudah dikonfigurasi dan respon yang lebih cepat yang dapat diandalkan. Secara aplikasi teknologi EXP8 sama dengan OVT8 yaitu mampu melakukan kontrol, alarm check dan simulasi kontrol tetapi ada perbedaan yang sangat jauh pada kedua sistem tersebut mulai dari kemampuan memproses dataa dan trasfer data yang dari kedua hal itu mempengaruhi temperatur dari suatu sistem. Berikut adalah gambar produk dan sistem konfigurasi untuk produk EXP8 sebagi referesi penulis menganalisa sistem

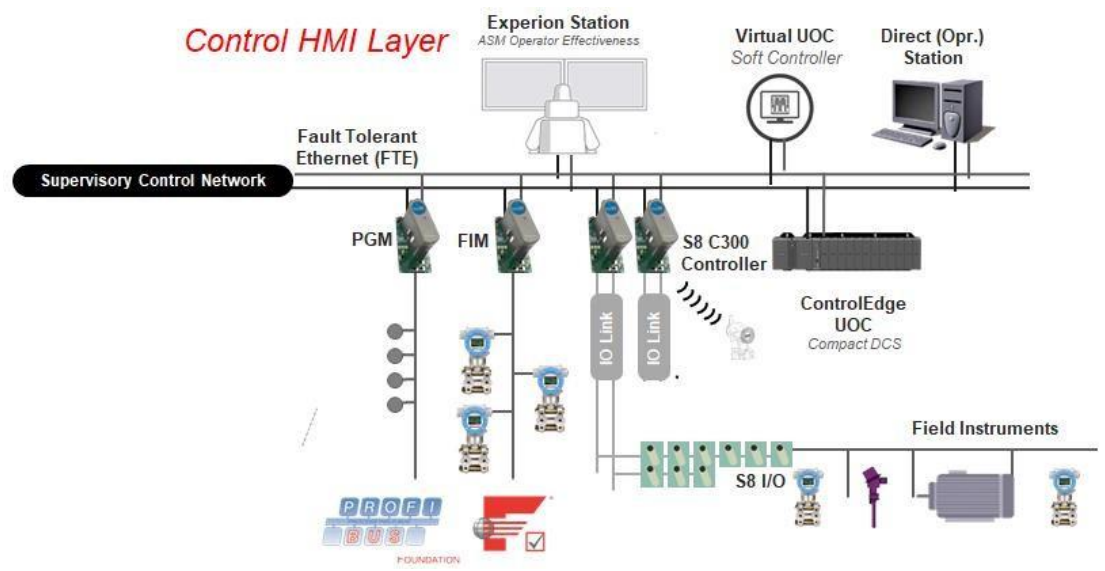

Gambar 3. Sistem arsitektur EXP8 
Tabel 1. Perbandingan spesifikasi alat

\begin{tabular}{|c|c|c|}
\hline Deskripsi & OVT 8 & EXP 8 \\
\hline IO CAPACITY & 3200 Maximum & 2000+8000 Scada Poin \\
\hline TAG & $\begin{array}{l}1024 \text { direct wired } 2048 \text { direct wired } \\
\text { signal }\end{array}$ & 10000 Process 800 Scada \\
\hline Station & 254 Drop & 15 Direct \\
\hline System Display & YES & YES \\
\hline Alaraming & YES & YES \\
\hline History & YES & YES \\
\hline Trending & YES & YES \\
\hline Station Server & YES & YES \\
\hline Network Interface & Ovation $100 \mathrm{MB}$ High way & $\begin{array}{l}\text { FTE Single/Redundant } \\
\text { Ethernet }\end{array}$ \\
\hline SCADA Interface & Via Ethernet IP & $\begin{array}{l}\text { Modbus TCP/IP,MGR } \\
\text { SIL3,DNP3 }\end{array}$ \\
\hline OPC & OPC Client & $\begin{array}{l}\text { OPC Client, DA Server, } \\
\text { Matrikon }\end{array}$ \\
\hline Controller & OCR 400 dan OCR 161 (10-30 ms) & $\mathrm{C} 30050 \mathrm{~ms}$ \\
\hline $\begin{array}{l}\text { Ace Software } \\
\text { Controller }\end{array}$ & Ovation R3.0 solaris system & No \\
\hline Simulation & Ovation Simulation & C300 Simulator \\
\hline Safety Controller & Delta V SIS & $\begin{array}{l}\text { Safety MGR (SIL3) } \\
\text { HC900SIL2 }\end{array}$ \\
\hline IO Family & $\begin{array}{l}\text { Ovation } 13 \text { Bit Input } \\
\text { Ovation } 14 \text { Bit output }\end{array}$ & $\begin{array}{l}\text { Series } 8 \text { IO } \\
\text { Redundance Simplex }\end{array}$ \\
\hline HART & YES & YES \\
\hline Profibus & YES & YES \\
\hline $\begin{array}{l}\text { Foundation Field } \\
\text { Bus }\end{array}$ & YES & YES (Segment Key) \\
\hline ASI & NO & YES \\
\hline Batch & NO & YES \\
\hline Advance Control & Fuzzy Control, Smart sootblowing & $\begin{array}{l}\text { Profill Loop, CAP, } \\
\text { Autotuning }\end{array}$ \\
\hline
\end{tabular}

Tabel 2. Analisa beda rata-rata varians untuk temperatur

\begin{tabular}{|c|c|c|}
\hline & $\begin{array}{l}\text { Tempertatur } \\
\text { EXP8 }\end{array}$ & $\begin{array}{c}\text { Temparatur } \\
\text { OVT } 8\end{array}$ \\
\hline Mean & 23.003 & 16.9 \\
\hline Variance & 0.22 & 0.607 \\
\hline Observation & 400 & 400 \\
\hline Hypotize Mean & 0 & \\
\hline diference & & \\
\hline Df & 655 & \\
\hline t Stat & 3.661 & \\
\hline $\mathrm{P}(\mathrm{T}<=\mathrm{t})$ one-tail & 0.00013 & \\
\hline t Critical one-tail & 1.647 & \\
\hline $\mathrm{P}(\mathrm{T}<=\mathrm{t})$ Two-tail & 0.00027 & \\
\hline t Critical Two-tail & 1.963 & \\
\hline
\end{tabular}


Tabel 3. Analisa beda rata-rata varians untuk kecepatan proses data

\begin{tabular}{lrr}
\hline & $\begin{array}{c}\text { Kecepatan } \\
\text { Proses Data } \\
\text { EXP8 }\end{array}$ & $\begin{array}{c}\text { Kecepatan } \\
\text { Proses } \\
\text { Data } \\
\text { OVT 8 }\end{array}$ \\
\hline Mean & 20514.65 & 21341.35 \\
Variance & 156635.76 & 495323.92 \\
Observation & 30 & 30 \\
Hypotize Mean & 0 & 0 \\
diference & 46 & \\
Df & 5.607 & \\
t Stat & 5.58 & \\
P $(T<=t)$ one-tail & 1.678 & \\
t Critical one-tail & 1.116 & \\
P $(T<=t)$ Two-tail & 2.0128 & \\
t Critical Two-tail & & \\
\hline
\end{tabular}

Tabel 4. Analisa beda rata-rata varians untuk kecepatan transfer data

\begin{tabular}{lrr}
\hline & $\begin{array}{c}\text { Kecepatan } \\
\text { Transfer } \\
\text { Data } \\
\text { EXP8 }\end{array}$ & $\begin{array}{c}\text { Kecepatan } \\
\text { Transfer } \\
\text { Data } \\
\text { OVT 8 }\end{array}$ \\
\hline Mean & 0.29 & 0.368 \\
Variance & 0.128 & 0.13 \\
Observation & 30 & 30 \\
Hypotize Mean & 0 & 0 \\
diference & 58 & \\
Df & -0.835 & \\
t Stat & 0.203 & \\
P $(T<=$ t) one-tail & 1.671 & \\
t Critical one-tail & 0.406 & \\
P $(T<=$ t) Two-tail & 2.001 & \\
t Critical Two-tail & & \\
\hline
\end{tabular}

Tabel 5. Rata-rata dan simpangan baku dari variabel pengukuran

\begin{tabular}{cccc}
\hline CS / Variabel & Temperatur & $\begin{array}{c}\text { Kecepatan } \\
\text { data } \\
\text { Proses }\end{array}$ & $\begin{array}{c}\text { Kecapatan } \\
\text { Pengiriman Data }\end{array}$ \\
\hline EXP8 Mean & $23.003^{\circ} \mathrm{C}$ & 0154.65 byte & $0,2908 \mathrm{Mb}$ \\
EXP8 Stdv & 0.78 & 395.77 & 0.36 \\
OVT8 Mean & $16.9^{\circ} \mathrm{C}$ & 1341.35 byte & $03684 \mathrm{Mb}$ \\
OVT8 Stdv & 0.47 & 705.8 & 0.36 \\
\hline
\end{tabular}


Tabel 6. Hasil Anaslisa variabel pengukuran

\begin{tabular}{|c|c|c|c|c|}
\hline Variabel & Jitung & Tabel & Analisa Hipotesa & Kesimpulan \\
\hline Temperatur & 3.661 & 1.963 & hitung $>$ t- tabel) & $\begin{array}{c}\mathrm{H}_{1}: \mu_{1} \neq \mu_{2}: \text { Ada perbedaan an } \\
\text { OVT } 8\end{array}$ \\
\hline $\begin{array}{r}\text { cepatan } 1 \\
\text { Dat }\end{array}$ & 5.607 & 2.012 & -hitung > t-tabel) & $\begin{array}{c}\mathrm{H}_{1}: \mu_{1} \neq \mu_{2}: \text { Ada perbedaan antara EXP8 dan } \\
\text { OVT8 }\end{array}$ \\
\hline $\begin{array}{l}\text { Kecepatan } \\
\text { Transfer Data }\end{array}$ & 0.835 & 2.001 & -hitung < t-tabel) & $\begin{array}{c}H_{0}: \mu_{1}=\mu_{2}: \text { Tidak ada perbedaan antara EXP8 } \\
\text { dan OVT8 }\end{array}$ \\
\hline
\end{tabular}

Berdasarkan dari tabel diatas maka di dapat sebagai berikut :

Kepasitas input dan output dari OVT8>EXP8 dimana jumlah tag pad OVT 8 lebih besar dari EXP8. Kapasitas station untik kontrol OVT8 >EXP8 dimana OVT mencapai 254 Drop di EXP8 hanya 15 Station..

Network Interface OVT8 Menggunakan 100Mb High way dan untuk EXP8 menggunakan FTE( LX Native Device) $100 \mathrm{Mb}$, tetapi data yang ditransfer lebih kecil dari OVT8 kerena sistem komunikasi yg dipakai berbeda.

SCADA komunikasi untuk OVT8 menggunakan jalur Ethernet I/P dan OPC Client sedangkan untuk EXP8 menggunakan jalur Modbus komunikasi dan OPC Client, hal ini dikarenakan EXP8 untuk komunikasi data kapasitasnya lebih kecil.

Controller Untuk OVT8 menggunakan controler tipe OCR-400 dengan kecapatean 10-30 ms dan untuk EXP8 menggunakan C300 untuk controller nya dengan kecepatan 50 ms. Dari kecepatan menunjukan OVT8 lebih cepat dibandingkan dengan EX8 sesuai dengan perhitungan pengambilan data.

Software untuk OVT8 menggunakan individual software dimana saat ini OVT8 menguanakan develop software dari solaris sedangkan untuk EXP8 tidak menggunakan software khusus hanya mengembangkan dari System Windows sehingga bisa mengurangi biaya pembelian dan pemeliharaan.

Pengembangan Produk setelah Benchmark dari semua data yang telah didapatkan lalu di analisa penulis mecobamemberikan saran untuk dapat mengembangkan produk lebih bersaing dan diterima oleh konsumen dan penulis menyarankan untuk perbaikan pada produk EXP8 agar bisa mendapatkan produk yang lebih baik untuk kompetitor nya OVT8 diantaranya sebagai berikut

Melakukan perubahan pada komponen elektronika untuk memproses data agar proses data bisa lebih cepat dan jumah data yang diolah lebih banyak.

Melakukan perbaikan design panel agar bisa mengurangi panas yang dihasilkan oleh controller saat proses kalkulasi berlangsung.

Membuat suatu software khusus untuk melakukan kalkulasi dalam memproses data lapangan agar perhitungan data bisa lebih baik dan hasil perhitungan yang didapat untuk pengontrolan tersebut bisa lebih cepat.

Melakukan improvisasi dengan meningkatkan sistem teknologi network yang terbaru untuk meningkatkan kapasitas kemampuan transfer data, karena saat ini trasnsfer data (Network) masih menggunakan sistem lama.

\section{KESIMPULAN}

Dari hasil penelitian yang dilakukan dengan metoda perbandingan (Benchmarking) antara dua Produk DCS untuk meningkatkan kualitas produk PT HL yaitu DCS EXP8 didapatkan hasil sebaagi berikut:

Penelitaian menggunakan variabel perbandingan Temperatur, Keceapatan proses data Keceapatan transfer data didapat perbedaan antara kedua produk di variabel temaperatur dan kecepatan proses data, sedangkan untuk kecepatan transfer data masih sama. Hal ini bisa dijadikan acauan untuk perusahaan produk DCS EXP8 untuk memperbaiki kedua variabel tersebut

Untuk bisa digunakan di dunia industri produk DCS harus bisa memenuhi standar temperatur yang 
dihasilkan saat proses kalkulalasi dimana temperature diharapkan tidak terlalu panas dan diperlukan rekayasa infrastruktur untuk komunikasi yang baik sehingga transfer data bisa lebih baik.

Pengunnaan sistem redundant atau disebut jutas Back up system agar alat siap setiap saat.

Penganturan jumlah input dan output oleh sistem DCS agar data bisa lebih maksimal.

Penggunaan aplikasi redundant di sistem komunikasi dan transfer data.

Memperbaiki sistem kalkulasi dalam program agar proses data lebih cepat serta desain komponenpendukung agar temperatur produk bisa baik.

Dari hal diatas untuk bisa meningkatkan penjualan produk selain hal teknis diperukan juga sistem marketingpengenalan produk pada konsumen sehingga produk ini bisa lebih di kenal di masyarakat.

\section{DAFTAR PUSTAKA}

Adewale A.A., Dike I.(2013) Fan Speed Control Of Processor Base on Enviromental Termperature. International Journal of Scientific and Engineering Research, Volume 4, 11. Department of Electrical and Information Engineering, Covenant University, Ota Nigeria.

Amolo T.,Kirui.(2013) Heat Dissipation in a Computer. Journal of Energy and Policy. Volume 2 No.6Department of Physic Egerton University. Njoro Kenya

Frost and Sullivan.(2009) World Distribution Control System (DCS) Market. Frost and Sullivan, US.

Kanaon,K.,Spainhower,L.(2008) Dependability Benchmark for Computer System .IEEE Computer Society, JohnWilley \& Son, Hoboken, New Jersey.

Lamancusa,.J.S.(1992) Journal Product Dissection-A Tool for Benchmarking in The Process of TeachingDesign, Department of Mechanical Engineering, Pennsylvania State University, US.

National Research Council.(2007), Benchmarking the competitiveness of United State in Mechanic Engineering Basic Research, National Academies Press Washington D.C

Purbayu,B.S.(2005), Analisis Statistik dengan Ms Excel dan SPSS, Penerbit Andi, YogyakartaRidwan .(2013). Dasar Dasar Statistik, Penerbitan Alfabeta, Geger Kalong Hilir, Bandung.

Sherp.M (2007). E-Commerce Benchmarking Guide 2007, Marketing Sherpa Inc. Wamen USA Sutherland, Andrew.(2008) Benchmarking the Otomative Industry in Central and Eastern Europe: Creating andPreserving Value for Long Term, KPMG, Central Eastern Europe.

Waluyo, Sihono D.(2001), Statatistika untuk Pengambilan Keputusan, Penerbit Ghalia Indonesia, Jakarta.

Watson, G.H.(1997) Strategic Benchmarking Mengukur Kinerja Perusahaan anda Dibandingkan denganperusahaan terbaik Dunia. PT Gramedia Pustaka Utama.Jakarta. 